DOI https://doi.org/10.18551/rjoas.2020-09.10

\title{
CORPORATE SOCIAL RESPONSIBILITY IN RELATION TO THE COMMON AGRICULTURAL POLICY IN THE GREEK FOOD AND BEVERAGE INDUSTRY
}

\author{
Demestichas Konstantinos $^{1 *}$, Remoundou Konstantina ${ }^{2}$, Xenokostas Christos ${ }^{1}$, \\ Costopoulou Constantina ${ }^{1}$ \\ ${ }^{1}$ Department of Agricultural Economics and Rural Development, \\ Agricultural University of Athens, Athens, Greece \\ ${ }^{2}$ Institute of Communication and Computer Systems, National Technical University of Athens, \\ Athens, Greece \\ *E-mail: cdemest@aua.gr \\ ORCID: 0000-0002-8858-6389
}

\begin{abstract}
The purpose of this paper is to study the way in which Greek enterprises in the food and beverage sector promote their corporate social responsibility actions in social media (e.g. Facebook and Twitter) and to what extent they meet the requirements of the Common Agricultural Policy. The materials and methods employed involved the collection and analysis of data from a sample of 219 Greek companies in the food and beverage sector. Data were collected from the corporate social media accounts, using a manual survey over a period of two months, as well as using a popularity analysis tool. The analysis of the data has led to the extraction of useful conclusions, for both Large and Small/Medium sized companies, regarding the promotion of corporate social responsibility across social media, as well as the focus given on the priorities of the Common Agricultural Policy of the European Union, including environmental issues such as energy efficiency, climate protection and environmental standards, as well as societal issues such as the well-being of personnel, safety at work and compliance with social guidelines. Results show that large companies carry out a significantly higher number of corporate social responsibility actions, promoting them though social media, in comparison to Small/Medium enterprises. Moreover, the large majority of corporate social responsibility actions that have been performed are related to the priority of sustainable management of natural resources and actions for the climate of the Common Agricultural Policy, whereas the priority of non-mutated materials gathers has attracted less interest.
\end{abstract}

\section{KEY WORDS}

Agricultural industry, corporate social responsibility, common agricultural policy, Common European Policy, social media networking, sustainable development.

Corporate Social Responsibility (CSR) is one of the most dynamic and demanding areas of activity for modern businesses and refers to the actions of companies that aim to address environmental and social issues. To date, the literature on CSR and, especially, in the agricultural industry lacks various aspects and there is no common definition of CSR, or rather a consensus on what the concept actually means for the agricultural industry.

According to Thanopoulos (2003), "modern business must be aware of the way of thinking and the pace of the social environment and to adapt its mode of action according to the generally accepted principles of the space in which it operates". As business ethics and social responsibility have become one of the main strategic goals in most corporations, it has become widely understood that the production of goods in the form of products or services is not enough anymore to meet the needs of the consumer; initiatives are also required that meet the general socio-economic needs within the community, where households and businesses co-exist (Bassen et al., 2005).

The evolution of CSR is directly linked to developments in the fields of technology, communication and globalization of the market, forcing businesses to constantly try to 
expand their activities and take on more responsibilities. CSR gives the opportunity for businesses to maximize their value and consolidate their reputation, with a greater emphasis on the social and environmental aspects of their operations. A company maximizes its value when it takes into account not only the interests of shareholders, but also the interests of other "partners", such as employees, suppliers and society.

In order to accomplish such a mission, most companies have chosen to advertise and publish their activities in CSR through social media, such as Facebook and Twitter. According to Baird (2011), social media offer the opportunity for "the democratization of information, since through their use, people become 'publishers' of the information rather than mere readers". On the other hand, social media also provide the opportunity to businesses to mine data about the users' preferences and opinions regarding their brand, products and services, and to take more informed management decisions.

Hence, the present paper addresses a series of core research questions regarding CSR activities, such as: in what volume and extent do the companies use the social media for their activities, what are those activities in particular, and where do they mostly focus on, are the environmental activities one of the main focus points of the companies, etc.

In particular, the remaining part of this paper is organized as follows: In Section 2, the definition and the connection of CSR with the Common Agricultural Policy is presented, whereas Section 3 explains the use of the social media for the communication of CSR activities to the general public. Section 4 focuses on a preliminary study that was performed, while Section 5 refers to the research methodology and results of the main survey conducted, regarding the CSR-related use of Facebook by the Greek food and beverage companies. Finally, Section 6 concludes the paper.

Corporate Social Responsibility and Common Agricultural Policy. Nowadays, consumer criticism of agricultural activity has become more and more intense due to the growing ecological consciousness, reflecting the notion that the agricultural activity is not uninvolved in terms of social and ecological prospects. There are not many things more important to European citizens than the safety and stability of food supplies produced in ways that ensure sustainable land use and environmental protection. Therefore, CSR in agriculture has been the subject of open public debate for a long time.

In general, the notion of CSR for the agricultural industry does not yet a commonly agreed definition. Heikkurinen and Forsman-Hugg (2011) as well as Maloni and Brown (2006) have identified and described key aspects of CSR in the agricultural industry. Both studies refer to the well-being of animals, the food quality, the environment, as well as health and safety, as important factors. Moreover, they refer to aspects of CSR related to the safety of products, the presence in local markets, the financial responsibility in biotechnology, employment, human rights, supplies, and the community at large.

Common Agricultural Policy (CAP), which faces many new economic, social and environmental challenges, is proving that agriculture is moving towards sustainable development. The concept of CSR can play a key role in addressing these challenges. Changing conditions in the agricultural market create different regulatory needs for participants. Effective implementation of agricultural policy presupposes the adaptation of applied tools to these needs. The new challenges of agricultural policy required the implementation of some CAP reforms, most of which were set in 2009 and 2013 (Massot, 2020).

The stated challenges can be attributed to three groups of factors, which in many cases are external to agriculture. These groups of factors have been identified as follows:

- economic (including food security and globalization, declining productivity growth rates, price volatility, production cost pressures due to high input prices and deteriorating farmers' position in the food supply chain);

- related to soil and water quality and threats to habitats and biodiversity; and

- land-related (where rural areas are experiencing demographic, economic and social development, including population abandonment and business relocation).

The concept of CSR acts as a tool to meet such challenges, because CSR implies that a company voluntarily assumes responsibility for society. The agricultural industry is under 
increasing public scrutiny. Issues related to intensive livestock farming (such as good animal welfare), environmental aspects of production (such as reducing water and energy consumption, or social aspects such as working conditions) are becoming increasingly important to society. The industry's critical approach by various stakeholders (e.g. nongovernmental organizations, the media, political decision-makers and the general public) can threaten the reputation and legitimacy of individual companies and the industry as a whole.

Therefore, although social demands and the need for CSR characterize many industries, the agricultural industry can be considered as key, due to the wide range of problems mentioned, the negative publicity of the media debate and the extreme intensity of public interest, which render this industry a prime example of an in-depth analysis of the status quo and future research needs regarding CSR.

Heyder and Theuvsen (2008) were also able to show, through a survey of 170 companies from the agricultural industry, that size affects a company's efforts for CSR. Agricultural companies operating in other countries should be aware that the attitudes of stakeholders on various issues, such as the use of Genetically Modified Organisms (GMOs) and the good treatment of animals or labor rights, may differ significantly. They recognized different requirements for businesses depending on their degree of internationalization.

The use of Social Media in Corporate Social Responsibility. Information quality and speed are essential in today's new world of media messaging. The increased customer access to information through social media is probably one of the most challenging issues that businesses are faced with today. Listening to customers by introducing new media requires "new" learning approaches from organizations. Adapting in this new era, many businesses around the world have started to do just that, over the past 10-15 years, quickly integrating "new" social media channels into the marketing communication mix.

Social media include a variety of online media platforms using social networking sites such as Facebook, Twitter and Linkedln, video sharing sites such as YouTube and photo sharing sites such as Instagram, Flicker and Picasa. Such social media can be used for the promotion of CSR, in conjunction with or as an alternative to self-promotion through traditional media. For the purposes of promoting CSR, significantly different communication styles need to be considered and applied. Such strategies might range from the use of social media as simple messaging tools up to incorporating them as the heart and soul of the CSR strategy, seamlessly integrating them as part of the corporate brand. Although businesses have begun exploring the use of social media to promote their organizational "values", the vast majority of businesses still do not. For the most part, they are trying to connect social media with more traditional advertising efforts.

On every continent except Asia, Twitter is the most widespread social media platform. On the other hand, blogs are the least used among social media. The story is clear, that is, the shorter answers are much preferred over the more prepared text of a blog with the expected longer response times. The United States, Europe and Latin America seem to be the most advanced in the development and use of social media, while Asia is moving in their direction.

Unilever, for example, has developed its program for CSR with the key message that small actions make a big difference. Its program for CSR is known as the "Sustainability Plan" (The Guardian, 2011). The company uses three social media platforms, YouTube, Twitter and Facebook, to communicate CSR messages. The campaign focuses on three aspects: individuals, the planet and profits. Unilever is also making a strong case for why CSR is good in a business sense.

Even smaller businesses like Patagonia (The Footprint Chronicle) may excel in communicating work related to CSR. Patagonia is dedicated to sustainability and its emblematic program for CSR is known as "The Footprint Chronicle" (Polley, 2011). Consumers can identify the effects of products from design through delivery to see how green the company is. Innovative communication efforts with CSR, such as The Footprint Chronicle, have helped Patagonia double its sales in recent years and increase its profits as consumers have become more willing to support companies with a real understanding of environmental issues. 
Initial Study. In the context of this paper, 219 companies in the Food and Beverage sector were initially studied for the period 18/01/2018 to 28/02/2018, $112(51,2 \%)$ of which appear on social media. Of the 52 major Greek companies - based on international standards for the size of businesses - 38 have a presence on social media, which translates into a percentage of $73 \%$. Of the 167 small and medium-sized enterprises, only 74 have a page on a social networking site, which translates into a percentage of $44 \%$.

As shown in Table 1, 84\% (32 out of a total of 38 companies) of the major Food and Beverage companies have a preference on Facebook and $71 \%$ (27 out of a total of 38 companies) use YouTube. 26\% (10 out of 38 companies) use Twitter, 24\% (9 out of 38 companies) have a presence in Instagram and Linkedln, while Pinterest (8\%, 3 out of 38 companies) holds the smallest percentage of preference. Also, Google+ was used by some companies before its termination (16\%, 6 out of 38 businesses).

The data gathered from small and medium-sized enterprises from the Food and Beverage sector show that Facebook attracts the largest interest (93\%), while the next most popular medium is YouTube (with $47 \%$ ). Twitter is used by $38 \%$, Instagram by $27 \%$, Linkedln by $19 \%$, Google+ (before its discontinuation) by $16 \%$ and last in preference with $5 \%$ comes Pinterest.

Lastly, in the preferences of all Greek food and beverage companies (regardless of size), Facebook is largely preferred by $90 \%$ of the companies, while YouTube comes second in preference with 55\%. Twitter (34\%), Instagram (26\%), Linkedln (22\%) and Google+ (before its discontinuation) (16\%) follow in line, with the least preferred being Pinterest with $6 \%$ of the companies using it.

Table 1 - Percentage of companies using social media, as determined in the initial study

\begin{tabular}{llllllll}
\hline Companies & Facebook & Twitter & Instagram & Linkedln & YouTube & Pinterest & Google+ \\
Large & $84 \%$ & $26 \%$ & $24 \%$ & $24 \%$ & $71 \%$ & $8 \%$ & $16 \%$ \\
Small-Medium & $93 \%$ & $38 \%$ & $27 \%$ & $19 \%$ & $47 \%$ & $5 \%$ & $16 \%$ \\
Total & $90 \%$ & $34 \%$ & $26 \%$ & $22 \%$ & $55 \%$ & $6 \%$ & $16 \%$ \\
\hline
\end{tabular}

Description and Results of Main Survey. A second (main) study was subsequently conducted in the same year, in the context of this paper, for which the corresponding research and the data collection were carried out between 01/08/2018 and 30/09/2018. The basis of this research is the sample of 219 companies' active in the Food and Beverage sector, studied in-between 18/01/2018 to 28/02/2018 (see previous section).

Firstly, information about the Food and Beverage companies that have implemented CSR actions and also have a page either on Facebook or Twitter (Table 2) was collected. These companies were surveyed according to the degree of promotion of CSR actions on Facebook and Twitter. In particular, relevant information was collected regarding their CSRrelated publications on these social media, and especially the type of publication they chose to make (i.e. text, video, event, post and image). Depending on their purpose and content, the CSR actions were then classified into four main categories: environment, society, human resources, and multiple actions.

Moreover, especially the actions that focused on the environment were encoded into four specific categories, in order to allow their evaluation according to the degree of harmonization with the philosophy of CAP for sustainable development, transparency and security of the supply chain. Accordingly, the four categories that were defined are:

1. sustainable management of natural resources and climate action (protection of soil, water, air);

2. balanced territorial development (support for outdoor employment);

3. ensuring the health and well-being of people and animals; and

4. GMOs (implementation of a policy of non-mutated materials - animal feed).

A specialized tool that measures the activity of users is Likealyzer (McNamee, 2020), which contains five measurement categories from which "Activity" was studied. Activity has the following features: Posts per Day, Photo, Notes, Videos, Liked Pages. Using Likealyzer, the results depicted in Table 3 were retrieved. 
Table 2 - Percentage of Food \& Beverage companies on Facebook and/or Twitter

\begin{tabular}{llll}
\hline Companies & Number & Facebook & Twitter \\
Large & 52 & $32(61,5 \%)$ & $11(21,2 \%)$ \\
Small-Medium & 167 & $69(41,3 \%)$ & $27(16,2 \%)$ \\
Total & 219 & $101(46 \%)$ & $38(17,35 \%)$ \\
\hline
\end{tabular}

Table 3 - Categorization of Food \& Beverage companies depending on their Facebook Activity (\%)

\begin{tabular}{llll}
\hline Activity & Number of companies & Large & Small-Medium \\
$0 \%$ & 17 & $1(6 \%)$ & $16(94 \%)$ \\
$1-20 \%$ & 7 & $0(0 \%)$ & $7(100 \%)$ \\
$20-40 \%$ & 8 & $4(50 \%)$ & $4(50 \%)$ \\
$40-60 \%$ & 38 & $16(42 \%)$ & $22(58 \%)$ \\
$60-80 \%$ & 10 & $4(40 \%)$ & $6(60 \%)$ \\
$80-100 \%$ & 8 & $6(75 \%)$ & $2(25 \%)$ \\
Total & 88 & $31(35 \%)$ & $57(65 \%)$ \\
\hline
\end{tabular}

As depicted in Table 2, out of the total of 219 companies in the Food and Beverage sector, 101 companies have a Facebook page, but only 88 companies showed some activity on Facebook during the evaluation period (i.e. 13 companies demonstrated no activity). Furthermore, out of these companies, those that implemented CSR actions which they made public amounted to 44 (a percentage of $21 \%$ out of the total of 219 companies).

The search concerning environmental posts was performed on the Facebook pages using keywords such as: society, social, environment, ecology, ecological, sustainable development, sponsor, sponsorship, actions, nature, volunteers, volunteering, offering, supporting, competitions, athletes, sports, corporate social responsibility, corporate responsibility.

The results of the search were classified into four main categories, namely companies that have made $0,1-5,5-30$ and over 30 posts of CSR actions on Facebook. More specifically, the results of this categorization were the following:

- 10 companies had 0 posts for CSR actions on Facebook;

- 8 companies had 1-5 posts of CSR actions on Facebook;

- 18 companies had 6-30 posts of CSR actions on Facebook;

- 8 companies had more than 30 publications of CSR actions on Facebook.

Table 4 - Frequency of Facebook posts related to CSR from the Food \& Beverage companies

\begin{tabular}{lllllll}
\hline \multirow{2}{*}{ Companies } & \multirow{2}{*}{ Number of companies } & \multicolumn{2}{l}{ Number of posts } & & \\
& 0 & $1-5$ & $6-30$ & $>30$ & Total \\
Large & 52 & $3(5,8 \%)$ & $3(5,8 \%)$ & $13(25 \%)$ & $6(11,5)$ & $25(48 \%)$ \\
Small-Medium & 167 & $7(4,2 \%)$ & $5(3 \%)$ & $5(3 \%)$ & $2(1,2 \%)$ & $19(11,4 \%)$ \\
Total & 219 & $10(4,6 \%)$ & $8(3,7 \%)$ & $18(8,2 \%)$ & $8(3,6 \%)$ & $44(21 \%)$ \\
\hline
\end{tabular}

These 44 companies that maintain a Facebook page and at the same time implemented and publicized CSR actions, have developed 123 CSR actions, 56 of which focused on Environment (45.5\%), 27 on Society (22\%), 19 on Human Resources (15.5\%) and 21 on Multiple Actions (17\%).

More specifically, out of the 56 CSR actions focused on the Environment, the distribution was as follows:

- 28 focused on Action 1 (50\%), for the sustainable management of natural resources and actions for the climate (protection of soil, water, air);

- 14 focused on Action 2 (25\%), for balanced territorial development (support for outdoor employment);

- 12 focused on Action 3 (21,50\%), ensuring the health and well-being of humans and animals;

- 2 focused on Action $4(3,50 \%)$, i.e. the implementation of a policy of non-mutated materials and animal feed (GMOs). 


\section{CONCLUSION}

Changes in social conditions, accelerated by globalization, have created new social demands and new conditions for businesses. Consumers, especially in developed societies, are increasingly concerned about the social and ecological aspects of production processes. Respectively, the growth and rising importance of social media has led to greater transparency and increasing public relations activities of companies. The corporate world has started to embrace this power, develop social media communication strategies and, above all, use social media as a trademark and tool of corporate brand. CSR is no longer an occasional charity provided to local communities but can be a powerful brand that reaches millions worldwide.

The purpose of this paper was to study how Greek food and beverage companies promote the CSR activities they implement through their corporate websites and to what extent they meet the CAP's aspirations. The results of the survey showed that:

1. to a large extent, companies do not take advantage of the targeted visibility that they can enjoy on Facebook in specific categories of audience with low financial costs and high reciprocal benefits;

2. the difference between Large and Small/Medium-sized Food and Beverage companies is significant, with the Large Enterprises using the potential of social media to a much greater extent. These findings are in line with the results of Demestichas et al. (2019) for the CSR in the Greek agri-food industry;

3. the majority of companies do not fully appreciate the vital role that corporate responsibility can play in sustainable and uninterrupted development and the positive cascading effects that these actions can bring;

4. the differentiation between Large and Small/Medium Food and Beverage companies at this point is significant, with the Large Companies having assimilated to a large extent the philosophy of the CSR, in contrast to the Small and Medium enterprises, which are typically performing fragmentary actions. In particular, although carried out on their corporate website, the promotion of CSR activities through Facebook posts is not a strategic choice for most companies, which seem to under-value the importance that CSR actions hold for the general public and their impact on consumer choices;

5. the large majority of companies typically harmonize CSR actions with CAP guidelines on sustainable natural resource management and mitigating climate change (soil, water, air protection, etc.), while less focus is placed on harmonization with guidelines related to balanced territorial development or for ensuring the health and well-being of humans and animals;

6. the implementation of policies of non-mutated materials and animal feed (GMOs) is also of very low priority.

\section{REFERENCES}

1. Baird, C. H., \& Parasnis, G. (2011). From social media to social customer relations management. Strategy \& Leadership, 39(5), 30-37.

2. Bassen, A., Jastram, S., \& Meyer, K. (2005). Corporate Social Responsibility.

3. Bloom, P. N., \& Perry, V. G. (2001). Retailer power and supplier welfare: The case of Wal-Mart. Journal of Retailing, 77(3), 379-396.

4. Demestichas, K., Costopoulou, C., Ntaliani, M., Remoundou, K., Adamopoulou, E., \& Papagiannaki, A. (2019). Corporate social responsibility in the agri-food sector: evidence from Greece. Journal of Agricultural Informatics, 10(2), 48-59.

5. Heikkurinen, P., \& Forsman-Hugg, S. (2011). Strategic corporate responsibility in the food chain. Corporate Social Responsibility and Environmental Management, 18(5), 306316.

6. Heyder, M. \& Theuvsen, L. (2008). Legitimating business activities using Corporate Social Responsibility: Is there a need for CSR in agribusiness?. System Dynamics and Innovation. 
7. McNamee, H. (2020). What Happened To LikeAlyzer.com?. https://theecommmanager.com/what-happened-to-likealyzer/, Acc. 1 September, 2020.

8. Maloni, M. J., \& Brown, M. E. (2006). Corporate social responsibility in the supply chain: An application in the food industry. Journal of Business Ethics, 68(1), 35-52.

9. Massot, A. (2020). The common agricultural policy - instruments and reforms. European Parliament Fact Sheets.

10. Polley, L. (2011). Introducing the New Footprint Chronicles on Patagonia.com. https://www.patagonia.com/stories/introducing-the-new-footprint-chronicles-onpatagoniacom/story-18443.html, Acc. 1 September, 2020.

11. The Guardian (2011). Unilever Sustainable Living Plan. The Guardian. https://www.theguardian.com/sustainable-business/unilever-sustainable-living-plan, Acc. 1 September, 2020.

12. Thanopoulos, G. (2003). Corporate Ethics and Code of Conduct. Interbooks publications, Athens. 